\title{
Prevalence of Thyroid Dysfunction Among Asymptomatic Elderly Filipinos at the Philippine General Hospital
}

\author{
Margarita Victoria Holgado-Galicia, Hallert C. Ramos, Cecilia A. Jimeno \\ Section of Endocrinology, Diabetes and Metabolism, Philippine General Hospital, Manila, Philippines
}

\begin{abstract}
The elderly are a peculiar group in terms of health management, as they often present with non-specific complaints which are challenging to interpret and may not present with the usual clinical picture of a disease.

Objective. The study aims to determine the prevalence of thyroid dysfunction among asymptomatic, elderly Filipinos seen at the Philippine General Hospital (PGH).

Methodology. Subjects aged 60 years and older seeking out-patient medical consult for non-thyroidal illness at the PGH were recruited. Patients with known thyroid or pituitary disease, previous thyroid or pituitary surgery, intake of medications known to affect thyroid hormone levels and critical illness were excluded. Fasting blood sugar (FBS), lipid profile, free thyroxine (FT4), thyroid-stimulating hormone (TSH), and anti-thyroperoxidase (anti-TPO) levels were taken. Based on FT4 and TSH levels, subjects were classified as overt hypothyroid, subclinical hypothyroid, euthyroid, subclinical hyperthyroid, or overt hyperthyroid.
\end{abstract}

Results. One hundred eighty subjects were recruited, of whom $152(84 \%)$ were female. Hypertension was the most common comorbidity (58.33\%), followed by diabetes (36.67\%). One hundred sixty-two (90\%) were euthyroid, 12 (6.7\%) subclinical hypothyroid, $4(2.22 \%)$ subclinical hyperthyroid, and two $(1.11 \%)$ overtly hyperthyroid. No one was overtly hypothyroid. There was a trend toward increasing prevalence of diabetes, hypertension, low HDL, obesity and overall cardiovascular risk among those with subclinical hypothyroidism.

Conclusion. Subclinical hypothyroidism was the most prevalent thyroid dysfunction among asymptomatic elderly included in the study.

Keywords: subclinical thyroid dysfunction, elderly, asymptomatic, Filipino, cardiovascular risk

\section{Introduction}

The elderly are frequently subjected to various tests in search for possible disease, as they often present with nonspecific complaints which are difficult to interpret. Oftentimes, results incidentally detect some metabolic abnormalities. Among these common incidental findings are abnormalities in the lipid profile, for which treatment to prevent cardiovascular events has been proven to have significant clinical impact in the last decade.

The Third Report of the National Cholesterol Education Program Adult Treatment Panel (NCEP-ATP III) recommends that any person with any form of hyperlipidemia must undergo evaluation to rule out secondary dyslipidemia prior to initiation of therapy. ${ }^{1}$ Despite this guideline, local physicians do not commonly screen for other causes as seen in a quality of care assessment performed at the PGH General Medicine clinic, where screening for secondary causes of dyslipidemia, such as hypothyroidism and chronic liver disease was the lowest among the quality of care indicators for dyslipidemic patients. $^{2}$

\section{ISSN 0857-1074}

Printed in the Philippines

Copyright (C) 2012 by the JAFES

Received February 20, 2012.Accepted April 11, 2012.
The NCEP-ATP III cites hypothyroidism as one of the major causes of secondary dyslipidemia. Hypothyroidism is diagnosed by an elevated serum TSH level. ${ }^{1}$ When accompanied by low FT4 and free triiodothyronine (FT3) levels, the condition is considered overt hypothyroidism; normal FT4 and FT3 in the presence of elevated TSH is termed subclinical hypothyroidism. In the latter case, since symptoms of hypothyroidism may not necessarily be present, it is sometimes more aptly referred to in literature as mild hypothyroidism, mild thyroid dysfunction, or moderate thyroid failure. ${ }^{3}$ It is a common incidental finding in the general population, particularly in select groups such as women and the elderly. The prevalence of subclinical hypothyroidism has been shown to increase with age in various epidemiologic studies, making it a major concern among the elderly (defined locally as those above 60 years old).4-6 While the approach to overt hypothyroidism is straightforward, subclinical hypothyroidism poses a management dilemma and has been a subject of contention among clinicians for years.

Various studies have related aging with thyroid function. With increasing age, there is an increasing prevalence of

Corresponding author: Margarita Victoria Holgado-Galicia, MD

Address: 49 Don Rufino Ave., Tahanan Village, Parañaque City 1700

E-mail address: marvi.holgado@gmail.com 
antithyroid antibodies, as well as abnormalities in circulating thyroid hormone and TSH levels characteristic of "non-thyroidal illness" syndrome due to age-associated diseases. An age-dependent decline in thyroid function is also observed independent of the "non-thyroidal illness."

Different prevalence rates among the elderly have been reported in foreign literature, ranging from 1.4 to 7.8 , to as high as $21 \% .4,8$ An Italian epidemiologic study involving 916 participants aged 65 years and above showed that the prevalence of overt hypothyroidism was $0.6 \%$, subclinical hypothyroidism $2.7 \%$, overt hyperthyroidism $1.6 \%$, and subclinical hyperthyroidism $7.8 \% .^{5}$ There is scant data from local studies. A study done on 161 institutionalized elderly Filipinos reported only the prevalence of overt and subclinical hypothyroidism. ${ }^{9}$ Unpublished data from the Philippine Thyroid Disorders Prevalence Study (PhilTiDes) have reported a prevalence rate of $0.4 \%, 2.2 \%, 0.6 \%$, and $5.3 \%$ for overt hypothyroidism, subclinical hypothyroidism, overt hyperthyroidism, and subclinical hyperthyroidism, respectively, for the general study population. No age-related prevalence rate was available. ${ }^{10}$

The relationship between dyslipidemia and overt hypothyroidism is already well-established. However, there is conflicting data on the association of lipid disorders with subclinical hypothyroidism. In a study by Hueston and Pearson on 215 subjects with subclinical hypothyroidism, they found no statistically significant association between subclinical hypothyroidism and serum cholesterol or triglyceride levels after adjustment for confounding variables. ${ }^{11}$ Similarly, in a Japanese study on 2,865 subjects, there was no significant difference in total serum cholesterol levels of subclinical hypothyroid and euthyroid subjects. ${ }^{12}$ However, in the Colorado Thyroid Disease Prevalence Study involving 25,862 individuals, a statistically significant trend towards increasing serum cholesterol, triglycerides, and lowdensity lipoprotein (LDL) was seen across the different thyroid disease states as the TSH level increased. Moreover, a significantly higher proportion of subclinical hypothyroid subjects had elevated total cholesterol levels compared to those with normal thyroid function. ${ }^{5}$

Cardiovascular disease and mortality have also been associated with subclinical hypothyroidism. An increase in the incidence of ischemic heart disease, atherosclerosis and myocardial infarction in both elderly men and women with subclinical hypothyroidism was found in the Rotterdam Study and the reanalysis of the Whickham Survey. ${ }^{13,14}$ Imaizumi also reported an increase in all-cause mortality on follow-up studies of elderly patients with subclinical hypothyroidism. ${ }^{12}$

Data on the benefits of intervention have likewise been conflicting. A cross-sectional study of 66 subjects with subclinical hypothyroidism showed no significant improvement in dyslipidemia with levothyroxine therapy. ${ }^{8}$ McDermott and Ridgway, on the other hand, found benefit with levothyroxine therapy among subclinical hypothyroid subjects with improvement of their hypothyroid symptom score, based on the results of three randomized controlled trials. ${ }^{15}$ A quantitative review of literature published in 2000 showed a decrease in mean serum total and LDL cholesterol concentrations among 247 subjects with subclinical hypothyroidism given levothyroxine therapy. Improvement was more pronounced for those with higher cholesterol levels at baseline, but no significant effects were seen in serum high-density lipoprotein (HDL) or triglyceride concentrations. ${ }^{16}$ A reanalysis of the Whickham Survey showed an attenuation of ischemic heart disease (IHD)related morbidity and mortality with following treatment of subclinical hypothyroid subjects with levothyroxine. ${ }^{14}$

A Consensus Development Conference, composed of a panel of 13 experts ( 8 in the field of thyroid disease and 5 in other fields of research and medicine), was convened on September 2002 to resolve issues on the diagnosis and management of subclinical thyroid disease. The group released guidelines and recommendations against population-based screening and routine treatment of subclinical thyroid disease due to lack of sufficient evidence to support their benefit. ${ }^{17}$ However, the American Association of Clinical Endocrinologists, the American Thyroid Association and The Endocrine Society reviewed the recommendations of the panel and published a consensus statement in 2005. The statement recommended routine screening for subclinical thyroid dysfunction for the general population, especially in specific groups, such as pregnant women and those contemplating pregnancy. Treatment for most patients with subclinical hypothyroidism and some with subclinical hyperthyroidism was also advised. ${ }^{18}$

The elderly population in the Philippines is increasing at an exponential rate annually. Filipino senior citizens, defined as those aged 60 years and older, have increased in number from 3.19 million in the early 1990's to 4.6 million by the following decade. This trend is in parallel with an increase in cardiovascular events - similar to that observed in the Western world-where an increasing prevalence of cardiovascular events is noted with increasing age. Given a greater prevalence of subclinical thyroid dysfunction noted among the elderly compared to the general population, this can also be anticipated with the growing elderly population in the Philippines. ${ }^{3}$

\section{Rationale}

Cardiovascular disease is a major health problem and is particularly more prevalent in the elderly. The control of modifiable risk factors such as dyslipidemia has resulted in a decrease in the occurrence of cardiovascular events. Subclinical thyroid dysfunction, a known cause of secondary dyslipidemia, has also been shown to be more 
prevalent in the elderly. As such, it is a potential target for intervention in order to decrease cardiovascular risk and events.

The study by Awayan in 1998 looked at the prevalence of subclinical hypothyroidism in institutionalized elderly subjects. No correlation with cardiovascular risk was established. ${ }^{18}$ To our knowledge, no local study has been done to date on the prevalence of subclinical thyroid dysfunction and its association with cardiovascular risk in the general elderly population.

\section{Objectives}

\section{Primary objective}

The objective of the study is to determine the prevalence of thyroid dysfunction (overt and subclinical hypothyroidism, and overt and subclinical hyperthyroidism) among asymptomatic Filipino elderly subjects seen at the PGH Outpatient Department.

\section{Secondary objectives}

The study also aims to describe the lipid profile, coexistent cardiovascular disease [IHD, cerebrovascular disease (CVD) and heart failure], and cardiovascular risk factors (hypertension, diabetes and smoking) among asymptomatic Filipino elderly in each category of thyroid dysfunction.

\section{Methodology}

This is a cross-sectional analytical study with the following inclusion and exclusion criteria:

\section{Inclusion criteria}

1. Filipinos aged 60 years and older

a. With informed consent to participate in the study

\section{Exclusion criteria}

1. Diagnosed thyroid illness and/or history of treatment (medical, surgical, nuclear, or radiation therapy) for thyroid illness

2. History of surgery or radiation of the thyroid for non-thyroid related illness (e.g. laryngeal cancer)

3. Diagnosed pituitary disease and/or history of pituitary surgery

4. Intake of medications known to affect thyroid hormone levels (e.g. amiodarone, steroids, antipsychotics)

5. Critical illness

Individuals aged 60 years or older seeking outpatient medical consult at the PGH for conditions other than thyroid illness, or those accompanying patients seeking consult, were recruited for the study. Inclusion and exclusion criteria were checked at the time of recruitment. Companions of patients who fit the inclusion criteria were also recruited to participate in the study.
After informed consent was obtained, general clinical data and anthropometric measurements were taken by the investigator. Identification of known cardiovascular disease and risk factors (e.g. diabetes, IHD, CVD, hypertension and heart failure) was done by examination of medical records - if available-and through taking the medical history. Medications taken by the recruited subjects were noted to aid in the identification of cardiovascular comorbidities and risks. The subjects were asked to return on another day after a 10-hour fast for determination of FBS, lipid, TSH, FT4 and anti-TPO levels.

Radioimmunoassay technique was used to measure FT4, TSH and anti-TPO levels. The normative values used were 11 to $24 \mathrm{pmol} / \mathrm{L}$ and 0.3 to $3.8 \mathrm{mIU} / \mathrm{L}$ for FT4 and $\mathrm{TSH}$, respectively. A positive anti-TPO was a level above $50 \mathrm{U} / \mathrm{mL}$. Based on the levels of FT4 and TSH, subjects were classified into one of the following categories:

\begin{tabular}{lcc} 
& & \\
\hline \multicolumn{1}{c}{ Category } & TSH & FT4 \\
Overt hypothyroid & $>3.8 \mathrm{mlU} / \mathrm{L}$ & $<11 \mathrm{pmol} / \mathrm{L}$ \\
Subclinical hypothyroid & $>3.8 \mathrm{mIU} / \mathrm{L}$ & $11-24 \mathrm{pmol} / \mathrm{L}$ \\
Euthyroid & $0.3-3.8 \mathrm{mIU} / \mathrm{L}$ & $11-24 \mathrm{pmol} / \mathrm{L}$ \\
Subclinical hyperthyroid & $<0.3 \mathrm{mIU} / \mathrm{L}$ & $11-24 \mathrm{pmol} / \mathrm{L}$ \\
Overt hyperthyroid & $<0.3 \mathrm{mIU} / \mathrm{L}$ & $>24 \mathrm{pmol} / \mathrm{L}$ \\
\hline
\end{tabular}

\section{Sample size calculation}

Data from the InCHIANTI study was used to compute for the estimated sample size, due to the lack of local data on the prevalence rate of thyroid dysfunction among the elderly. ${ }^{6}$ Based on prevalence rates in the elderly of $0.6 \%$, $2.7 \%, 1.6 \%$, and $7.8 \%$ for overt hypothyroidism, subclinical hypothyroidism, overt hyperthyroidism, and subclinical hyperthyroidism, respectively, a sample size of 173 was computed to yield a 95\% confidence interval and 5\% margin of error in detecting prevalence. A sample size of 307 is needed to establish association between variables, with a $95 \%$ confidence interval and 3\% margin of error.

\section{Data Analysis}

Baseline characteristics of the subjects were described using frequency and percentage. Anthropometric variables were reported as means and standard deviation (Table 1). The patients were classified by thyroid function based on TSH and FT4 levels, and the prevalence for each group was reported as frequency and percentages. Cardiovascular risk was computed based on the Framingham Point Score, which estimates the 10-year risk for coronary heart disease of an individual based on the gender, age, HDL level, systolic blood pressure, smoking and serum total cholesterol level. A score of less than $10 \%$ was categorized as low risk, 11 to $20 \%$ as intermediate risk, and more than $20 \%$ as high risk for the development of coronary heart disease within the next 10 years (Table 2).

Stata 9.2 software was used to analyze the data. Lipid profile and FBS values were reported as medians due to 
the large standard deviation obtained. The association of thyroid dysfunction with cardiovascular risk factors, as well as overall cardiovascular risk, were determined by Chi-square test. Cut-off values to determine abnormal lipid levels were based on the NCEP-ATP III criteria (total cholesterol more than $200 \mathrm{mg} / \mathrm{dL}$, LDL more than 130 $\mathrm{mg} / \mathrm{dL}$, triglycerides more than $150 \mathrm{mg} / \mathrm{dL}$ and HDL less than $40 \mathrm{mg} / \mathrm{dL}$.

\section{Results and discussion}

One hundred eighty subjects were included in the study. The mean age was 67.75 years, and majority were female $(84.44 \%)$. The most common cardiovascular comorbidity reported was hypertension $(58.33 \%)$, followed by diabetes $(36.67 \%)$. Only $10(5.56 \%)$ of the subjects were current smokers. $11.67 \%$ of the study population was categorized as high risk for cardiovascular disease (Table 1).

\begin{tabular}{lc}
$\begin{array}{l}\text { Table 1. Demographic and clinical characteristics of } \\
\text { the sample population. }\end{array}$ & $\begin{array}{c}\text { Frequency, (\%); mean } \pm \text { SD; } \\
\text { range } \\
\text { (n= 180) }\end{array}$ \\
\hline \multicolumn{1}{c}{ Characteristics } & $28(15.56)$ \\
Sex & $152(84.88)$ \\
Male & $67.75 \pm 6.7 ; 60-87$ \\
Female & $140.83 \pm 23.25 ; 90-220$ \\
Age (year) & $79.05 \pm 11.99 ; 50-110$ \\
Blood pressure & $24.26 \pm 4.1 ; 13.0-37.4$ \\
Systolic & $70(38.89)$ \\
Diastolic & $31(17.22)$ \\
Body mass index (kg/m $\left.{ }^{2}\right)$ & $65(36.11)$ \\
$<23$ & $14(7.78)$ \\
$23-24.9$ & $0.94 \pm 0.07 ; 0.7-1.15$ \\
$25-29.9$ & \\
$\geq 30$ & $66(36.67)$ \\
Waist-hip ratio & $105(58.33)$ \\
Co-morbidities & $23(12.78)$ \\
Diabetes mellitus & $11(6.11)$ \\
Hypertension & $10(5.56)$ \\
Ischemic heart disease & $21(11.67)$ \\
Cerebrovascular disease & \\
Smoker &
\end{tabular}

A majority (90\%) of the subjects had normal thyroid function. The most common thyroid dysfunction was subclinical hypothyroidism, noted in $6.67 \%$ of the study population. This was followed by subclinical hyperthyroidism $(2.22 \%)$ and overt hyperthyroidism $(1.11 \%)$. None were noted to be overtly hypothyroid (Table 2). Laboratory test results were given to the subjects within one month of release, either on their next out-patient consult or by telephone call and mail for those who were not seen within a month. No intervention was done for those who were noted to have subclinical thyroid dysfunction. Nevertheless, the subjects were advised to follow up at the PGH Thyroid Clinic for monitoring of thyroid function. Those found to have overt hyperthyroidism were likewise referred to the Thyroid Clinic for further management.

These findings differ from that observed in the InCHIANTI study, were the most commonly observed thyroid dysfunction in the study group was subclinical hyperthyroidism. ${ }^{6}$ This may possibly be due to the difference in profiles of the Italian and Filipino study populations, particularly in diet and rate of iodine excretion. The local prevalence study in the general population also observed subclinical hyperthyroidism as the most common thyroid dysfunction. However, the difference in the age groups of the subjects included may also account for the disparity in results. ${ }^{10}$

$\begin{aligned} & \text { Table 2. Classification of patients according to thyroid } \\
& \text { function }\end{aligned}$
\begin{tabular}{lc}
\multicolumn{1}{c}{ Thyroid Function } & Frequency (\%) \\
\hline Overt hypothyroid & $0(0 \%)$ \\
Subclinical hypothyroid & $12(6.67 \%)$ \\
Euthyroid & $162(90 \%)$ \\
Subclinical hyperthyroid & $4(2.22 \%)$ \\
Overt hyperthyroid & $2(1.11 \%)$ \\
\hline
\end{tabular}

Among the different subgroups, those who were found to have subclinical hyperthyroidism and hypothyroidism had the greatest proportion of anti-TPO (25\% and $16.67 \%$, respectively). This is consistent with another study which found that antithyroid antibodies increase with age.? Only $7.41 \%$ of those with normal thyroid function had antibodies (Table 3).

Table 3. Distribution according to gender and presence of anti-TPO

\begin{tabular}{|c|c|c|c|}
\hline \multirow[b]{2}{*}{ Thyroid Function } & \multirow{2}{*}{$\begin{array}{c}\text { Total } \\
\text { Samples }\end{array}$} & (+) Anti-TPO & Female \\
\hline & & $\begin{array}{c}\text { Frequency } \\
(\%)\end{array}$ & $\begin{array}{c}\text { Frequency } \\
(\%)\end{array}$ \\
\hline Overt hypothyroid & 0 & $-(-)$ & $--(-)$ \\
\hline Subclinical hypothyroid & 12 & $2(16.67)$ & $8(66.67)$ \\
\hline Euthyroid & 162 & $12(7.41)$ & $139(85.8)$ \\
\hline Subclinical hyperthyroid & 4 & $1(25)$ & $3(75)$ \\
\hline Overt hyperthyroid & 2 & $0(0)$ & $2(100)$ \\
\hline
\end{tabular}

Total cholesterol, LDL, and FBS levels were noted to be highest among those with subclinical hyperthyroidism; HDL and triglyceride levels were highest in those with overt hyperthyroidism (Table 4).

\begin{tabular}{|c|c|c|c|c|}
\hline Test & $\begin{array}{l}\text { Subclinical } \\
\text { hypothyroid }\end{array}$ & Euthyroid & $\begin{array}{l}\text { Subclinical } \\
\text { hyperthyroid }\end{array}$ & $\begin{array}{c}\text { Overt } \\
\text { hyperthyroid }\end{array}$ \\
\hline $\begin{array}{l}\text { Total cholesterol, } \\
\mathrm{mg} / \mathrm{dL}\end{array}$ & 187.15 & 214.77 & 261.915 & 190.7 \\
\hline Triglyceride, $\mathrm{mg} / \mathrm{dL}$ & 136.005 & 128.67 & 116.015 & 141.625 \\
\hline $\mathrm{LDL}, \mathrm{mg} / \mathrm{dL}$ & 114.36 & 139.55 & 191.69 & 113.14 \\
\hline $\mathrm{HDL}, \mathrm{mg} / \mathrm{dL}$ & 42.22 & 46.045 & 44.74 & 53.74 \\
\hline FBS, mg/dL & 86.47 & 91.395 & 102.435 & 84.335 \\
\hline
\end{tabular}

Differences in demographic and clinical characteristics among the subgroups showed that thyroid hormone levels inversely correlated with age, blood pressure levels, and obesity (Table 5). Those who were overtly hyperthyroid were younger, less hypertensive, and had normal BMI. On the other end, those who had subclinical hypothyroidism were generally older and more obese. 
Table 5. Demographic and clinical characteristics of subjects according to classification of thyroid function

\begin{tabular}{|c|c|c|c|c|}
\hline & $\begin{array}{l}\text { Euthyroid } \\
(n=162)\end{array}$ & $\begin{array}{l}\text { Subclinical hypothyroid } \\
(n=12)\end{array}$ & $\begin{array}{l}\text { Subclinical hyperthyroid } \\
(\mathrm{n}=4)\end{array}$ & $\begin{array}{l}\text { Overt hyperthyroid } \\
\qquad(n=2)\end{array}$ \\
\hline \multicolumn{5}{|l|}{$\operatorname{Sex}(\%)$} \\
\hline Male & $23(14.2)$ & $4(33.33)$ & $1(25)$ & $0(0)$ \\
\hline Female & $139(85.8)$ & $8(66.67)$ & $3(75)$ & $2(100)$ \\
\hline Age $($ mean $\pm S D)$ & $67.57 \pm 6,5$ & $70.67 \pm 9.4$ & $67.75 \pm 6.18$ & $65 \pm 4.24$ \\
\hline \multicolumn{5}{|l|}{ Blood pressure (mean $\pm S D$ ) } \\
\hline Systolic & $140.7 \pm 23.91$ & $140.83 \pm 18.32$ & $150 \pm 14.14$ & $135 \pm 7.07$ \\
\hline Diastolic & $79.26 \pm 11.82$ & $76.67 \pm 15.57$ & $82.5 \pm 5$ & $70 \pm 14.14$ \\
\hline $\mathrm{BMI}($ mean $\pm \mathrm{SD})$ & $24.2 \pm 4.09$ & $25.87 \pm 4.56$ & $23.49 \pm 1.39$ & $21.09 \pm 4.25$ \\
\hline Waist-hip ratio (mean $\pm \mathrm{SD}$ ) & $0.94 \pm 0.07$ & $0.94 \pm 0.06$ & $0.95 \pm 0.07$ & $0.92 \pm 0.05$ \\
\hline \multicolumn{5}{|l|}{ Co-morbidities (\%) } \\
\hline Diabetes mellitus & $59(36.42)$ & $6(50)$ & $1(25)$ & $0(0)$ \\
\hline Hypertension & 95 (58.64) & $8(66.67)$ & $2(50)$ & $0(0)$ \\
\hline $\mathrm{IHD}$ & $22(13.58)$ & $0(0)$ & $1(25)$ & $0(0)$ \\
\hline CVD & $10(6.17)$ & $0(0)$ & $1(25)$ & $0(0)$ \\
\hline Smoker (\%) & $10(6.17)$ & $0(0)$ & $0(0)$ & $0(0)$ \\
\hline Ten-year CV risk >20\% (\%) & $17(10.49)$ & $3(25)$ & $1(25)$ & $0(0)$ \\
\hline
\end{tabular}

There was no significant difference observed with the comparison of the presence of cardiovascular risk in patients with subclinical hypothyroidism and those with normal thyroid function. Lipid profile abnormalities were also not found to have any significant difference between the two subgroups (Table 6).

\begin{tabular}{|c|c|c|c|}
\hline $\begin{array}{l}\text { Cardiovascular risk } \\
\text { factor }\end{array}$ & $\begin{array}{c}\text { Subclinical } \\
\text { hypothyroid } \\
(\%) \\
\text { N }=12\end{array}$ & $\begin{array}{c}\text { Euthyroid } \\
(\%) \\
N=162\end{array}$ & $\begin{array}{c}\text { Chi-square } \\
\text { (p value) }\end{array}$ \\
\hline Diabetes mellitus & $6(50)$ & $59(36.42)$ & 0.348 \\
\hline Hypertension & $8(66.67)$ & $95(58.64)$ & 0.585 \\
\hline IHD & 0 & $18(13.58)$ & 0.172 \\
\hline CVD & 0 & $10(6.17)$ & 0.375 \\
\hline Heart failure & $1(8.33)$ & $6(3.70)$ & 0.431 \\
\hline $\begin{array}{l}\text { Total cholesterol > } 200 \\
\mathrm{mg} / \mathrm{dL}\end{array}$ & $6(50)$ & $106(65.43)$ & 0.281 \\
\hline $\mathrm{LDL}>130 \mathrm{mg} / \mathrm{dL}$ & $5(41.67)$ & $107(66.07)$ & 0.089 \\
\hline Triglyceride $>150 \mathrm{mg} / \mathrm{dL}$ & $4(33.3)$ & $65(40.12)$ & 0.643 \\
\hline $\mathrm{HDL}<40 \mathrm{mg} / \mathrm{dL}$ & $6(50)$ & $49(30.25)$ & 0.156 \\
\hline Smoking & 0 & $10(6.17)$ & 0.375 \\
\hline \multicolumn{4}{|l|}{$\begin{array}{l}\text { Overall cardiovascular } \\
\text { risk }\end{array}$} \\
\hline$>20 \%$ ten-year risk & $3(25)$ & $17(10.49)$ & 0.128 \\
\hline$<20 \%$ ten-year risk & $9(75)$ & $145(89.51)$ & 0.532 \\
\hline
\end{tabular}

\section{Conclusion}

Subclinical hypothyroidism is the most prevalent thyroid dysfunction among asymptomatic Filipino elderly patients seen at the PGH Outpatient Department, with a prevalence rate of $6.67 \%$, greater than that reported in foreign literature. ${ }^{6}$ There was a higher prevalence of diabetes, hypertension, obesity, low HDL and cardiovascular risk among asymptomatic elderly Filipinos with subclinical hypothyroidism compared to those who had normal thyroid function. A multivariate analysis could not yet be done at this point but completion of the computed sample size will allow for conclusive results regarding the association between thyroid dysfunction and cardiovascular risk. Limitations in funding restricted subject recruitment to the current study population.

\section{Acknowledgements}

This study was supported by a research grant from the Philippine Lipid and Atherosclerosis Society and the Philippine Society of Hypertension given in February 2010.

\section{References}

1. Third report of the National Cholesterol Education Program (NCEP) expert panel on detection, evaluation, and treatment of high blood cholesterol in adults (Adult Treatment Panel III) final report. Circulation 2002;106:3143421.

2. Tongol MR, Jimeno C, Acampado L. Assessment of the quality of care of patients with hypercholesterolemia seen at the Philippine General Hospital, General Medicine Clinic. Phil J Internal Medicine 2005;42:243-9.

3. Cooper DS. Subclinical hypothyroidism. N Engl J Med 2001;345(4):260-5.

4. Hollowell JG, Staehling NW, Flanders WD et al. Serum TSH, T(4), and thyroid antibodies in the United States population (1988 to 1994): National Health and Nutrition Examination Survey (NHANES III). J Clin Endocrinol Metab 2002;87(2):489-99.

5. Canaris GJ, Manowitz NR, Mayor G et al. The Colorado thyroid disease prevalence study. Arch Intern Med 2000;160(4):526-34.

6. Ceresini G, Lauretani F, Maggio M et al. Thyroid function abnormalities and cognitive impairment in elderly people: Results of the Invecchiare in Chianti study. J Am Geriatr Soc 2009; 57(1):89-93.

7. Mariotti S. Mild hypothyroidism and ischemic heart disease: Is age the answer? J Clin Endocrinol Metab 2008;93(8):2969-71.

8. Efstathiadou Z, Bitsis S, Milionis HJ et al. Lipid profile in subclinical hypothyroidism: Is L-thyroxine substitution beneficial? Eur J Endocrinol 2001;145(6):705-10.

9. Awayan AM, Justiniano GG, Oribio RU et al. Subclinical hypothyroidism in the elderly: A profile of residents in the home for the aged in Metro Manila. Phil J Internal Medicine 1998;36:307-11.

10. Carlos-Raboca J, Jasul GV, Kho SA et al. The Philippine thyroid disorders prevalence study (PhilTiDes). Unpublished data.

11. Hueston WJ, Pearson WS. Subclinical hypothyroidism and the risk of hypercholesterolemia. Ann Fam Med 2004;2(4):351-5.

12. Imaizumi M, Akahoshi M, Ichimaru S, et al. Risk for ischemic heart disease and all-cause mortality in subclinical hypothyroidism. J Clin Endocrinol Metab 2004;89(7):3365-70.

13. Hak AE, Pols HA, Visser TJ et al. Subclinical hypothyroidism is an independent risk factor for atherosclerosis and myocardial infarction in elderly women: The Rotterdam study. Ann Intern Med 2000;132(4):270-8.

14. Razvi S, Weaver JU, Vanderpump MP et al. The incidence of ischemic heart disease and mortality in people with subclinical hypothyroidism: Reanalysis of the Whickham Survey cohort. J Clin Endocrinol Metab 2010;95(4):1734-40.

15. McDermott MT, Ridgway EC. Subclinical hypothyroidism is mild thyroid failure and should be treated. J Clin Endocrinol Metab 2001;86(10):4585-90.

16. Danese MD, Ladenson PW, Meinert CL et al. Effect of thyroxine therapy on serum lipoproteins in patients with mild thyroid failure: A quantitative review of the literature. J Clin Endocrinol Metab 2000;85(9):2993-3001.

17. Surks MI, Ortiz E, Daniels GH et al. Subclinical thyroid disease: Scientific review and guidelines for diagnosis and management. JAMA 2004;291(2):228-38.

18. Gharib H, Tuttle RM, Baskin HJ et al. Consensus statement: Subclinical thyroid dysfunction: A joint statement on management from the American Association of Clinical Endocrinologists, the American Thyroid Association, and The Endocrine Society. J Clin Endocrinol Metab 2005;90(1):581-5. 